\title{
Developmental stress elicits preference for methamphetamine in the spontaneously hypertensive rat model of attention-deficit/ hyperactivity disorder
}

Jacqueline S. Womersley ${ }^{1 *}$, Bafokeng Mpeta ${ }^{1}$, Jacqueline J. Dimatelis ${ }^{1}$, Lauriston A. Kellaway ${ }^{1}$, Dan J. Stein ${ }^{2}$ and Vivienne A. Russell ${ }^{1}$

\begin{abstract}
Background: Developmental stress has been hypothesised to interact with genetic predisposition to increase the risk of developing substance use disorders. Here we have investigated the effects of maternal separation-induced developmental stress using a behavioural proxy of methamphetamine preference in an animal model of attentiondeficit/hyperactivity disorder, the spontaneously hypertensive rat, versus Wistar Kyoto and Sprague-Dawley comparator strains.

Results: Analysis of results obtained using a conditioned place preference paradigm revealed a significant strain $\times$ stress interaction with maternal separation inducing preference for the methamphetamine-associated compartment in spontaneously hypertensive rats. Maternal separation increased behavioural sensitization to the locomotor-stimulatory effects of methamphetamine in both spontaneously hypertensive and Sprague-Dawley strains but not in Wistar Kyoto rats.
\end{abstract}

Conclusions: Our findings indicate that developmental stress in a genetic rat model of attention-deficit/hyperactivity disorder may foster a vulnerability to the development of substance use disorders.

Keywords: Addiction, Attention-deficit/hyperactivity disorder, Conditioned place preference, Developmental stress, Methamphetamine, Spontaneously hypertensive rat

\section{Background}

Over recent years a substantial and compelling body of literature has emerged to suggest the importance of gene $\times$ environment interactions in the development of psychopathology. Genetic inheritance and environmental factors each account for approximately $50 \%$ of the risk of developing a substance use disorder (SUD) [1]. More specifically, both human and animal studies have identified early life stress and a diagnosis of attention-deficit/ hyperactivity disorder (ADHD) as individual risk factors

\footnotetext{
*Correspondence: jacqueline.womersley@gmail.com

1 Department of Human Biology, Faculty of Health Sciences, University of Cape Town, Anzio Road, Observatory, Cape Town 7925, South Africa Full list of author information is available at the end of the article
}

for the development of SUDs [2,3]. Specific mechanisms involved in such vulnerability have begun to be delineated in humans. A $\left[{ }^{11} \mathrm{C}\right]$ raclopride positron emission tomography study found that a history of childhood adversity increased amphetamine-induced dopamine release in the ventral striatum [4] while data from a functional magnetic resonance imaging (fMRI) study revealed increased limbic area activity after childhood maltreatment in abstinent methamphetamine-dependent individuals [5]. A further fMRI study examining reward-related brain areas found increased activity in the putamen in individuals who had experienced early life adversity whilst activity in the right insula was associated with ADHD symptomology [6]. Specific animal models may be useful in further investigating such mechanisms. Neonatal 
isolation-induced developmental stress in rats was found to increase cocaine self-administration [7]. In a separate study, developmentally stressed rats displayed a reduced threshold for intracranial self-stimulation of the lateral hypothalamus following amphetamine administration, an indication that the reward-enhancing effect of amphetamine was higher than in controls [8]. Combined these results suggest that early life stress and ADHD may render individuals hyper-sensitive to psychostimulants.

Though the shared pathophysiology underlying developmental stress, ADHD and SUDs is not yet clear, altered dopaminergic transmission affects all three processes and thus has emerged as a likely mechanism. Developmental stress induces long-term changes in the dopaminergic system, reducing dopamine type 2 receptor levels in the nucleus accumbens, which is in turn associated with compulsive drug use and impulsivity [9-11]. Altered striatal concentrations and functional polymorphisms of the dopamine transporter (DAT), the presynaptic transporter responsible for the rapid reuptake of synaptic dopamine and therefore of critical importance in dopaminergic homeostasis, have both been implicated in ADHD $[12,13]$. Furthermore, the most widely prescribed medications for the treatment of ADHD are psychostimulants, which exert their effects at dopaminergic synapses [14]. DAT is the molecular target for the psychostimulant drug of abuse, methamphetamine, which binds to DAT and reverses its action essentially causing dopamine to be released into, rather than taken up from, synapses [15]. The subsequent supraphysiological levels of dopamine are responsible for the rewarding properties of drugs and in turn influence a number of dopamine-dependent behavioural processes, which are comorbid with the development of SUDs, such as altered motivation, motor output, impulsivity and reward processing $[10,16]$.

To further probe the common mechanism underlying developmental stress, ADHD and SUDs, we previously used in vivo chronoamperometry to examine the effect of developmental stress, via maternal separation (MS), on striatal dopamine clearance in an animal model of ADHD. The spontaneously hypertensive rat (SHR), in comparison to its normotensive progenitor strain the Wistar Kyoto rat (WKY), is a well-validated animal model of ADHD [17-19]. Our preliminary results indicated that MS delayed the clearance of ejected dopamine in SHR suggesting reduced DAT efficiency [20]. A further study examining the effect of cocaine, a psychostimulant and potent DAT inhibitor, in this model found that the cocaine-induced delay in dopamine uptake was exacerbated by MS in SHR resulting in a prolonged elevated dopamine concentration [21]. Given these results, we hypothesise that the observed decrease in DAT efficiency in MS SHR will translate into an increased preference for the psychostimulant methamphetamine, a drug with a high potential for dependence and abuse [22]. We examined this proposal using SHR, WKY and an additional comparator strain, Sprague Dawley (SD), to control for the putative depressive/anxious phenotype of WKY, which might influence our results [23, 24]. This study used adolescent rats, an age associated with the onset of drug use and prior to the full development of elevated blood pressure in SHR [25, 26]. We employed the conditioned place preference (CPP) test, a classical conditioning paradigm that pairs drug exposure with one of two visually and tactilely distinct compartments to determine whether drug administration can overcome an innate initial preference. Successful pairing of a drug with the non-preferred compartment and a change in location preference is used as a proxy for the rewarding properties of the drug [27].

\section{Methods}

\section{Animals}

SHR (Charles River Laboratories, Wilmington, MA, USA), WKY (Harlan Laboratories, Bicester, UK) and SD (Charles River Laboratories, Wilmington, MA, USA) rats were obtained from strains maintained at the University of Cape Town Research Animal Facility. The decision to source WKY from Harlan, UK, rather than Charles River Laboratories, was based on research suggesting that they are the most appropriate behavioural and genetic control [24]. Rats had ad libitum access to water and standard rat chow and were housed in clear Perspex cages with wood chip bedding in a facility maintained at $21-23{ }^{\circ} \mathrm{C}$ with a $12 / 12 \mathrm{~h} \mathrm{light/dark} \mathrm{cycle} \mathrm{(lights} \mathrm{on} \mathrm{at} \mathrm{06h00).} \mathrm{All} \mathrm{experi-}$ ments were authorised by the University of Cape Town Faculty of Health Sciences Animal Ethics Committee under application 011/047 and conformed to local and international standards set out for the care and use of animals for scientific purposes $[28,29]$.

\section{Maternal separation}

The MS paradigm was performed as previously described [30]. Briefly, male and female rats were pair bred in the University of Cape Town Human Biology satellite animal facility and the day of birth of the resulting litters was designated as postnatal day 0 (P0). On P2, the dam was removed from the cage and the number and sex of the pups was determined. In order to maintain uniformity of care, litters were culled to 8 pups with males preferentially selected for. However, a minimum of 2 female pups were retained in each litter to control for possible altered maternal behaviour and subsequent anxiety in offspring due to varying litter gender composition [31, 32]. Dams of non-separated (nMS) litters were subsequently returned to the home cage and remained with 
the litter in the animal facility until weaning. Conversely, on P2 MS litters were removed from the dam to a separate room maintained at $31-33{ }^{\circ} \mathrm{C}$ with infrared heating lamps. Three hours later the litters were returned to the animal facility and the dam returned to the home cage. This separation paradigm occurred between $09 \mathrm{~h} 00$ and 13 h00 over 13 days from P2 to P14. Cleaning of cages and the initial handling of pups on P2 was consistent across MS and nMS groups to ensure that potential differences would be due to the effect of the separation paradigm. On P21 litters were weaned and male rats we co-housed (2-4 rats/cage) for the remainder of the project. No more than 2 rats from any one litter were assigned to an experimental group so as to avoid potential confounding litter effects.

\section{Conditioned place preference}

The CPP paradigm was performed over the course of 7 days (P54-P60) in male adolescent rats, thereby corresponding with the most common age of onset for SUDs in humans [33]. This compressed protocol consisted of 3 preconditioning, 3 conditioning and 1 probe trial day. Briefly, a square black Perspex box $(43 \mathrm{~cm}$ length $\times 50 \mathrm{~cm}$ height) was equally divided by a central partition to produce one chamber with a grid floor and thin vertical white stripes on the walls and a second chamber with unadorned walls and a smooth floor. Rats were allowed to freely explore the apparatus for 30 min during preconditioning, which was performed over the course of 3 days to compensate for the increased exploratory drive and preference for novelty in SHR as well as potential anxiety in WKY [34]. The compartment in which rats spent the most time on the 3rd day of testing was designated as the preferred compartment. The conditioning period was composed of $2 \times 1$-h trials per day with a vehicle $(0.9 \%$ saline administered via intraperitoneal injection at $1 \mathrm{ml} /$ $\mathrm{kg}$ volume) injection paired with the preferred compartment, and a methamphetamine (Sigma-Aldrich, St Louis, MO, USA) injection $(1.5 \mathrm{mg} / \mathrm{kg}$ in $0.9 \%$ saline administered via intraperitoneal injection at $1 \mathrm{ml} / \mathrm{kg}$ ) paired with the non-preferred compartment. These 2 trials were separated by at least $3 \mathrm{~h}$ to allow sufficient time for memory formation with the non-drug pairing conducted first to prevent the association of potential withdrawal effects with the subsequent trial [27]. The selected dose of methamphetamine $(1.5 \mathrm{mg} / \mathrm{kg}$ calculated as a free base) was based on 3 factors: successful CPP in SHR following conditioning with a $1.25 \mathrm{mg} / \mathrm{kg}$ dose; the failure to find an effect of MS on place preference in SD rats administered a $1.0 \mathrm{mg} / \mathrm{kg}$ dose; and the need to avoid potential neurotoxic side effects associated with a higher dose, which might reduce locomotor activity due to depressive effects [35-38]. As caudate putamen methamphetamine concentrations peak between 30 and 60 min post intraperitoneal injection, rats were injected $10 \mathrm{~min}$ prior to the onset of conditioning trials to ensure that peak cerebral concentrations of methamphetamine were reached within the $1 \mathrm{~h}$ conditioning trial [39]. On the final day of testing, P60, rats were exposed to a 30 min probe trial during which they were allowed to freely explore the apparatus. Behaviour was recorded using a Soni Handicam DCR-SX 83E and time spent in each compartment as well as locomotor activity were analysed using Noldus Ethovision XT 7.0 (Noldus Information Technology, Wageningen, Netherlands). This experimental design produced 6 final groups: nMS SHR $(\mathrm{n}=13)$, MS SHR $(\mathrm{n}=11)$, nMS WKY $(\mathrm{n}=10)$, MS WKY $(\mathrm{n}=13)$, nMS $\mathrm{SD}(\mathrm{n}=13)$ and MS SD $(\mathrm{n}=10)$.

\section{Statistical analyses}

All data were tested for normal distribution using a Shapiro-Wilk W test. Baseline activity data over the course of the 3 preconditioning days was analysed to check for strain and stress effects. The time spent highly mobile (defined as the period of time during which the area detected as the animal changes by at least $60 \%$ per second) was non-parametrically distributed and therefore tested for potential strain $\times$ stress effects using a Kruskal-Wallis test with multiple comparisons of mean ranks with Bonferroni adjustment as a post hoc test. To check for differences in the initial strength of compartment preference, the duration spent in the non-preferred compartment on the third day of preconditioning was subjected to a factorial ANOVA with strain and stress as categorical predictors. Significant differences were further investigated using a Tukey post hoc test. Methamphetamine preference scores were calculated by subtracting the time spent in the non-preferred compartment on the third day of preconditioning from the time spent in the same compartment during the probe trial. Therefore a positive value, i.e. increased time spent in the non-preferred compartment following methamphetamine conditioning, was taken as an indication of increased preference for the drug-paired compartment. Preference scores were normally distributed and thus analysed using a factorial ANOVA with strain and stress as categorical factors. Significant differences between groups were probed using a Tukey post hoc test. To determine which groups displayed behavioural sensitisation to methamphetamine, the total distance covered and the time spent highly mobile on the first and third days of conditioning were compared. As these data were non-parametrically distributed, they were analysed with a Wilcoxon Matched Pairs Test. To check for strain $\times$ stress effects on sensitisation, we subjected the mobility data to an aligned rank transform for 
nonparametric factorial analyses [40]. This preprocessing allows common ANOVA procedures to be used to investigate interaction effects in repeated measures nonparametrically distributed data. All statistical analyses were performed using Statistica 13 (Statsoft, Dell Software, Tulsa, OK, USA) and an $\alpha$ value of 0.05 was used to determine significance. Graphs were generated using GraphPad Prism 6.0 (GraphPad, La Jolla, CA, USA).

\section{Results}

The time spent highly mobile was recorded over the 3 preconditioning days and analysed to check for differences in baseline locomotor activity. Kruskal-Wallis tests revealed significant strain $\times$ stress effects on the time spent highly mobile on each of the 3 days [day $1 \mathrm{H}(5, \mathrm{~N}=70)=23.47$, $\mathrm{p}<0.001$; day $2 \mathrm{H}(5, \mathrm{~N}=70)=22.43, \mathrm{p}<0.001$; and day $3 \mathrm{H}(5, \mathrm{~N}=70)=26.27, \mathrm{p}<0.001]$ (Fig. 1). Post hoc analysis revealed that MS WKY spent less time highly mobile than MS SHR across all 3 days (day $1 \mathrm{p}=0.022$, day 2 $p=0.020$, and day $3 p=0.013$ ). MS WKY also spent less time highly mobile than MS SD on the third day of preconditioning $(\mathrm{p}=0.009)$. Further differences between SHR and WKY rats were also found on days 2 and 3 of preconditioning where nMS SHR spent more time highly mobile than nMS WKY $(\mathrm{p}=0.020$ and $\mathrm{p}=0.039$ respectively).

The change in time spent in the non-preferred compartment following methamphetamine administration was analysed by factorial ANOVA and revealed a significant strain $\mathrm{x}$ stress interaction $\left(\mathrm{F}_{(2,64)}=6.45, \mathrm{p}=0.003\right)$. A post hoc test indicated that MS SHR spent a longer period in the methamphetamine-paired compartment compared to both nMS SHR and MS SD $(\mathrm{p}=0.049$ and $\mathrm{p}=0.029$ respectively) (Fig. 2). MS did not alter

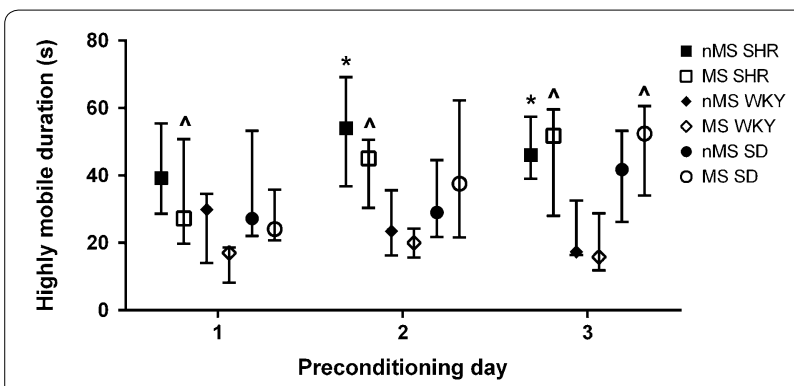

Fig. 1 SHR and WKY rats exhibit baseline differences in the time spent highly mobile during preconditioning. $\wedge$ MS WKY spent less time highly mobile compared to MS SHR on days 1 through 3 of preconditioning and compared to MS SD on the third day of preconditioning ( $p<0.05$, Bonferroni post hoc test). ${ }^{*}$ MMS WKY spent less time highly mobile than nMS SHR during the second and third days of preconditioning ( $p<0.05,613$ Bonferroni post hoc test). Data are displayed as median and interquartile range preference for the methamphetamine-paired compartment in either WKY or SD and no strain difference was found within the nMS group. The strength of initial compartment preference was analysed by factorial ANOVA and revealed a significant strain effect $\left(\mathrm{F}_{(2,64)}=10.36\right.$, $\mathrm{p}<0.001)$. A Tukey post hoc test indicated that WKY spent more time in the preferred compartment initially than both SHR and SD ( $<0.001$ and $\mathrm{p}=0.002$ respectively) (Fig. 2).

Potential sensitisation to methamphetamine was determined by comparing locomotor activity data obtained on the first and third days of methamphetamine conditioning. A Wilcoxon matched pairs test indicated an increase in time spent highly mobile on the third day of conditioning for all groups $\left(\mathrm{T}_{(\mathrm{n}=70)}=619.5, \mathrm{p}<0.001\right)$. This difference was significant in $\mathrm{nMS}$ SHR $\left(\mathrm{T}_{(\mathrm{n}=13)}=8.0\right.$, $\mathrm{p}=0.009)$, MS SHR $\left(\mathrm{T}_{(\mathrm{n}=11)}=2.0, \mathrm{p}=0.006\right)$ and MS $\mathrm{SD}\left(\mathrm{T}_{(\mathrm{n}=10)}=4.0, \mathrm{p}=0.028\right)$ (Fig. 3). A further Wilcoxon matched pairs test revealed a significant effect of methamphetamine on total distance covered in all groups $\left(\mathrm{T}_{(\mathrm{n}=70)}=640.0, \mathrm{p}<0.001\right)$, which was due to MS SHR and MS SD covering significantly greater distances on the third day of conditioning $\left(\mathrm{T}_{(\mathrm{n}=11)}=8.0, \mathrm{p}=0.026\right.$, and $\mathrm{T}_{(\mathrm{n}=10)}=6.0, \mathrm{p}=0.028$ respectively) (Fig. 4). Repeated measures ANOVAs of aligned rank transformed data revealed no significant strain $\times$ stress effects for either the duration highly mobile or the total distance covered.

\section{Discussion}

In this study we sought to investigate whether our earlier observation of delayed dopamine reuptake in MS SHR translates into increased preference for the psychostimulant methamphetamine measured using a CPP paradigm. Consistent with our hypothesis, MS SHR displayed increased preference for the methamphetaminepaired compartment compared to both nMS SHR and MS SD. The failure of MS in SD rats to increase methamphetamine preference is consistent with a previous study, in which nMS and MS male SD rats were exposed to 2 conditioning stages (P33-36 and P39-42) with methamphetamine (administered at $1 \mathrm{mg} / \mathrm{kg}$ ) yet did not differ in their preference for methamphetamine at P37, P43 or P50 [35]. The finding that WKY did not develop methamphetamine CPP is also in keeping with a previous study that showed that rats with high anxiety exhibit less $50 \mathrm{kHz}$ ultrasonic vocalizations-a marker of positive affect [41]. We also investigated whether there were any differences in the initial magnitude of compartment preference and determined that WKY showed a more robust preference for the saline-paired compartment during preconditioning than both SHR and SD rats. Perhaps more importantly for the current results, there was no difference in the strength of compartment preference 


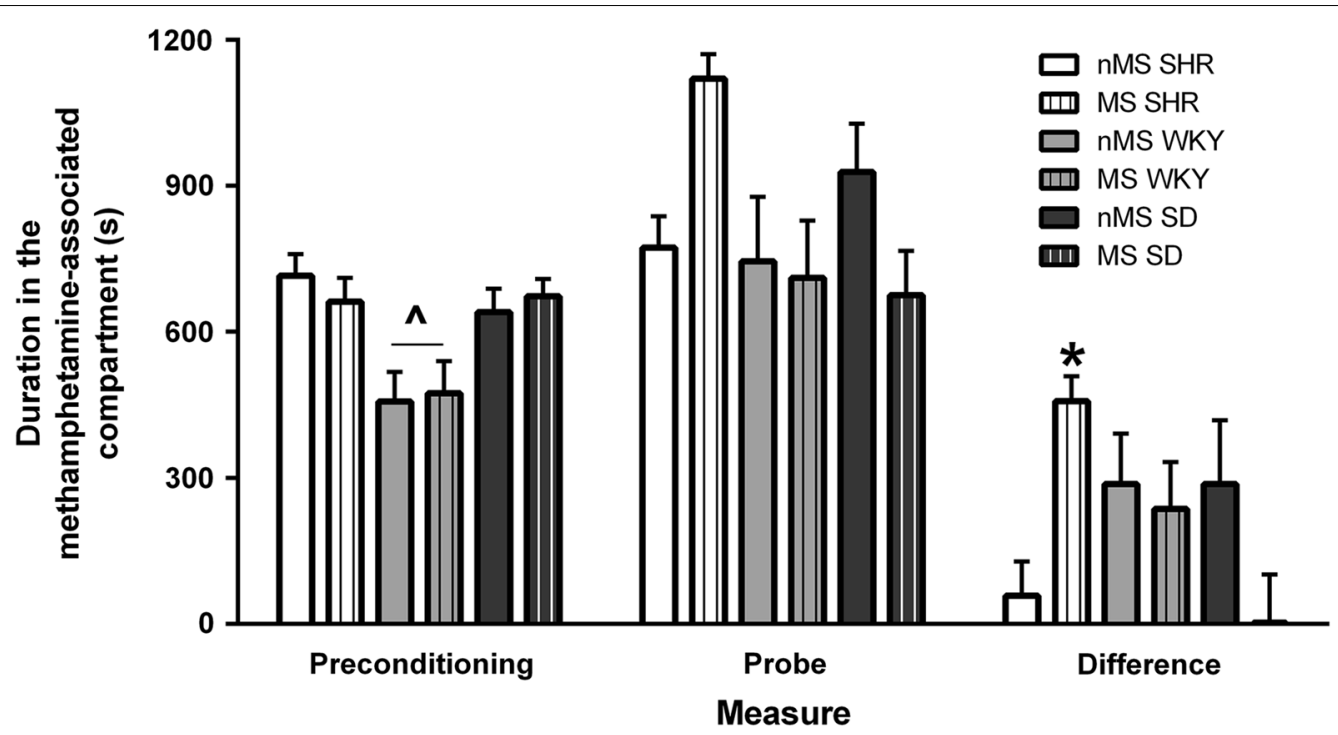

Fig. 2 MS SHR displayed preference for the methamphetamine-paired compartment. *The difference in time spent in the non-preferred/methamphetamine-paired compartment between the third day of preconditioning and the probe trial was greater in MS SHR than nMS SHR and MS SD ( $p<0.05$, Tukey post hoc test). $\wedge$ WKY displayed a stronger initial preference for the preferred compartment than both SHR and SD ( $p<0.05$, Tukey post hoc test). Data are displayed as mean \pm SEM

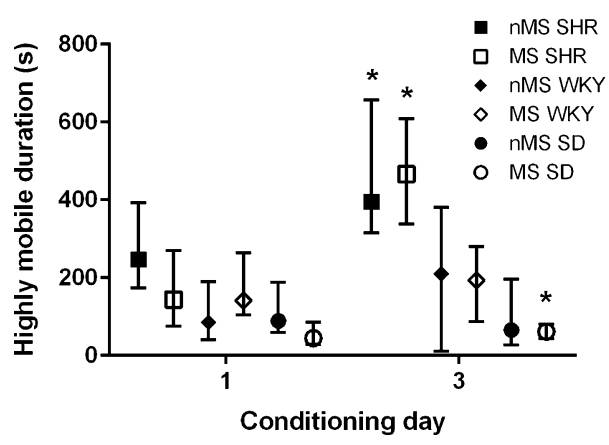

Fig. 3 SHR spent more time highly mobile after repeated methamphetamine administration. *nMS SHR, MS SHR and MS SD spent more time highly mobile on the third day of conditioning than on the first day ( $p<0.05$, Wilcoxon matched pairs test). Results are displayed as median and interquartile range

between nMS and MS SHR. Combined these results suggest that the influence of developmental stress on drug preference is dependent on genetic predisposition.

The failure of nMS SHR to show a robust preference for the methamphetamine-associated compartment is perhaps surprising given the association between ADHD and drug abuse [42]. However, we maintain that previous studies which found that SHR exhibit a preference for psychostimulants differ from our own in several important methodological aspects including the source of the SHR used and the age at testing. For example,

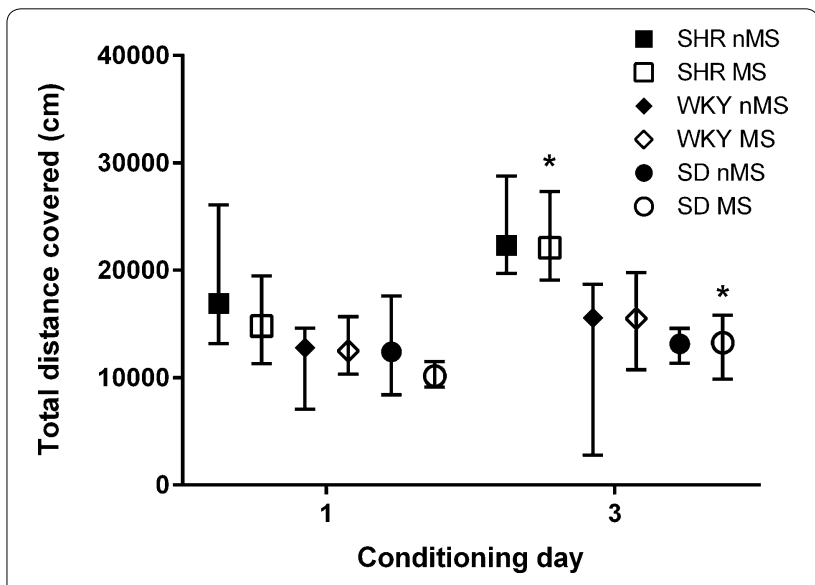

Fig. 4 MS increased locomotor activity after repeated methamphetamine administration in SHR and SD rats. ${ }^{*}$ MS SHR and SD travelled further on day 3 than on day 1 ( $p<0.05$, Wilcoxon matched pairs test). Results are displayed as median and interquartile range

several studies in SHR have found positive preference for methamphetamine $(1.25$ and $5.0 \mathrm{mg} / \mathrm{kg})$ as well as the psychostimulants amphetamine $(5 \mathrm{mg} / \mathrm{kg})$ and methylphenidate $(1.25,5.0$ and $20 \mathrm{mg} / \mathrm{kg}$ ) [37, 38, 43, 44]. Importantly, these studies made use of SHR obtained from Charles River Japan as opposed to the current study which sourced SHR from Charles River USA, a noteworthy distinction given evidence that suggests that SHR from different vendors may display different behavioural 
characteristics [24]. Furthermore, in the aforementioned studies, the age of the rats at the time of behavioural testing differed by at least a week compared to our protocol. Though a small difference, age has previously been suggested to influence the response to psychostimulants in SHR [45, 46]. A further possible reason for the failure to find methamphetamine CPP in nMS SHR in the current study lies in the behaviour of the strain. Previous research has indicated that, congruent with the hyperactive phenotype, SHR continue to display increased locomotor activity in familiar environments [47]. Indeed, an analysis of preconditioning baseline activity revealed that SHR were more active than their WKY counterparts. It is therefore possible that the rewarding effects of methamphetamine were insufficient to prevent nMS SHR from exploring both chambers of the apparatus during the probe trial.

A repeated measures analysis of the locomotor activity on the first and third days of conditioning found no significant strain $\times$ stress effects on the magnitude of sensitisation. However, a matched pairs comparison of locomotor activity on the first and third days of conditioning indicated that nMS SHR, MS SHR and MS SD spent more time highly mobile after repeated methamphetamine administration, which translated into an increased total distance covered in the latter two experimental groups. As these results measure the change in locomotor activity due to methamphetamine, they are not influenced by the higher baseline activity levels of SHR. This suggests that SHR, and in particular MS SHR, display an increased sensitisation to methamphetamine i.e. repeated exposure produces an increased stimulant drug response that is associated with increased motivation to consume the drug [48]. The current study made use of ambulatory activity to measure locomotor sensitisation. However, repeated exposure to psychostimulants may also lead to the development of repetitive motor behaviours or stereotypies such as repeated sniffing, rearing, and head and mouth movements [49]. Previous research using Lewis and Fischer 344 rats has indicated that the developmental time course of stereotyped behaviour in response to methamphetamine may differ between strains [50]. Furthermore, a study comparing the behavioural responses of 6 week old SHR and WKY to $d$-amphetamine found strain differences in the types of stereotypic movement produced [51]. It is therefore possible that an analysis of stereotyped behaviour in the current study may have revealed further strain and/or stress effects, including sensitisation to methamphetamine in WKY.

Comparison of the methamphetamine preference and sensitisation results reveal a conflict insofar as methamphetamine elicited preference in MS SHR whilst increasing sensitisation in nMS SHR, MS SHR and MS SD. This apparent contradiction between psychomotor and reward responses to psychostimulants has also been found in previous studies. One such investigation examined the effect of self-administration duration on drug-primed reinstatement and behavioural sensitisation [52]. Rats that advanced from short to extended access durations ( 1 vs. $6 \mathrm{~h}$ ) escalated their cocaine consumption during the first hour of their trials such that they infused more cocaine in that period than their short access $(1 \mathrm{~h}$ only) counterparts [52]. However, this group that displayed increased drug self-administration, a measure of drug preference, did not differ in locomotor sensitisation to the drug. Further, in a study that assessed locomotor activation, sensitisation and place preference in response to cocaine in 6 mouse strains, the authors failed to find locomotor sensitisation in certain strains that displayed drug CPP [53]. This led the authors to hypothesise that the psychomotor and rewarding effects of drugs may be served by distinct mechanisms. Extending this hypothesis to our own results, it is possible that developmental stress may exert different effects on these mechanisms within the strains we tested. Support for this explanation is provided by previous research suggesting that the time course of dopaminergic development differs between SHR and comparator strains. In an in vitro autoradiography study assessing striatal dopaminergic development in pre- and post-hypertensive (2 and 15 week old respectively) SHR and WKY, DAT was elevated in the caudate putamen of SHR at both developmental stages [54]. In addition, SHR putamen followed a lateral-to-medial DAT gradient during early development and displayed elevated dopamine type 1 receptor concentrations compared to WKY by 15 weeks [54]. A further study examining $\left[{ }^{3} \mathrm{H}\right]$ dopamine uptake into synaptosomes prepared from WKY and SHR (at 1, 2, 3, 6, 8 and 10 weeks of age) found that the rate of dopamine uptake in the prefrontal cortex was persistently lower in SHR from 2 weeks onwards and transiently lower in the striatum at the 6 week time point [55]. Though we were unable to find reports evaluating dopaminergic development in SHR and SD strains, the comparisons between SHR and WKY suggest possible strain differences in the developmental course of multiple dopaminergic pathways. It is therefore possible that the effects of MS may be region specific in different strains, based on the developmental stage of a particular brain area. In this way, MS may affect brain areas responsible for both locomotor activity and reward in SHR, whilst having a more anatomically restricted effect in influencing only locomotor activity in SD.

The potential of early life stress to exert long term changes on neurophysiology is well-recognised [56]. Of relevance to our MS model, immunohistochemical 
studies have indicated that development of the striatal dopaminergic system continues postnatally with an increase in axospinous connections and a decrease in axodendritic and axosomatic synapses [57]. The overall reduction in total dopaminergic synaptic density bears a closer resemblance to the adult profile [57]. Disruption during this critical window may produce psychopathology associated with dopaminergic dysfunction including ADHD and SUDs [58-60].

Both increased locomotor activity in response to methamphetamine and successful place preference are dependent on dopamine and as such these two measures can be used as a proxy of increased extracellular dopamine concentration $[16,61]$. Given the preference for and sensitisation to methamphetamine displayed by MS SHR, it is likely that developmental stress in SHR increased the extracellular dopamine concentration in the brain areas serving these functions. This would also be in keeping with our previous in vivo chronoamperometric studies where the DAT-mediated clearance of dopamine was delayed by MS in SHR [20, 21]. We hypothesise that the dose of methamphetamine used in the study $(1.5 \mathrm{mg} / \mathrm{kg})$ was non-saturating i.e. the number of DATs unimpeded by methamphetamine was reduced in MS SHR compared to controls. This scenario could result in a similar dopamine release between groups but prolonged elevated synaptic dopamine in MS SHR due to reduced DATmediated clearance. This is consistent with evidence for altered DAT function and responsiveness to psychostimulants in ADHD as found by Stein et al., where children diagnosed with ADHD and possessing the 9/9 repeat DAT allele were less sensitive to the effects of the therapeutic psychostimulants on measures of hyperactivity and impulsivity [62]. However, further experiments measuring methamphetamine-induced dopamine release and DAT-mediated reuptake would be required to either support or refute this proposed mechanism. This hypothesis would also be further refined by an experiment that examines whether MS affects DAT expression differently in SHR compared to WKY and SD.

\section{Conclusions}

Our finding of preference for the methamphetamineassociated compartment in MS SHR strongly supports our previous chronoamperometric findings of reduced DAT-mediated dopamine clearance in MS SHR. Given the high cost of SUDs to individuals and society, such mechanistic insights are important in understanding how a diagnosis of ADHD and a history of developmental stress may increase the risk of developing SUDs. Furthermore, these results again reinforce the importance of gene $\times$ environment interactions in influencing psychopathology.

\section{Abbreviations}

ADHD: attention-deficit/hyperactivity disorder; CPP: conditioned place preference; DAT: dopamine transporter; fMRI: functional magnetic resonance imaging; MS: maternally separated; nMS: non-maternally separated; P: postnatal day; SD: Sprague-Dawley; SHR: spontaneously hypertensive rat; SUD: substance use disorder; WKY: Wistar Kyoto.

\section{Authors' contributions}

JW, JD, LK, DS and VR conceived and designed the study. JW and BM conducted the experiments and analysed the data. JD, LK, DS and VR supervised the study. JW drafted the manuscript. All authors critically reviewed the manuscript and gave final approval for the version to be published. This work formed part of the BSC (Honours) project of BM and part of the Ph.D. thesis of JW. All authors read and approved the final manuscript.

\section{Author details}

${ }^{1}$ Department of Human Biology, Faculty of Health Sciences, University of Cape Town, Anzio Road, Observatory, Cape Town 7925, South Africa. ${ }^{2}$ Department of Psychiatry and Mental Health, Faculty of Health Sciences, University of Cape Town, Groote Schuur Hospital, Observatory, Cape Town 7925, South Africa.

\section{Acknowledgements}

Nuraan Ismail and AK Samuels are gratefully acknowledged for animal husbandry and care.

\section{Competing interests}

The authors declare that they have no competing interests.

\section{Availability of data and material}

The dataset supporting the conclusions of this article is available in the Zenodo repository, doi: 10.5281/zenodo.52569, https://zenodo.org/ record/52569\#.V0V3Cfl95NA [63]

\section{Ethics approval}

All experiments were authorised by the University of Cape Town Faculty of Health Sciences Animal Ethics Committee under application 011/047 and conformed to local and international standards set out for the care and use of animals for scientific purposes [28, 29].

\section{Funding}

This work was based on research supported by the South African National Research Foundation and the South African Medical Research Council. Any opinion, finding and conclusion or recommendation expressed in this material is that of the author and the NRF does not accept any liability in this regard. Thanks are also due to the Faculty of Health Sciences Research Committee of the University of Cape Town for their support and the Postgraduate Publication Incentive Award.

Received: 11 February 2016 Accepted: 9 June 2016

Published online: 17 June 2016

\section{References}

1. Maze I, Nestler E. The epigenetic landscape of addiction. Ann NY Acad Sci. 2011;1216:99-113.

2. Harstad E, Levy S. Attention-deficit/hyperactivity disorder and substance abuse. Pediatrics. 2014;134:e293-301.

3. Meade CS, Watt MH, Sikkema KJ, Deng LX, Ranby KW, Skinner D, Pieterse D, Kalichmann SC. Methamphetamine use is associated with childhood sexual abuse and HIV sexual risk behaviors among patrons of alcoholserving venues in Cape Town, South Africa. Drug Alcohol Depend. 2012;126:232-9.

4. Oswald LM, Wand GS, Kuwabara H, Wong DF, Zhu S, Brasic JR. History of childhood adversity is positively associated with ventral striatal dopamine responses to amphetamine. Psychopharmacology. 2014;231:2417-33.

5. Dean AC, Kohno M, Hellemann G, London ED. Childhood maltreatment and amygdala connectivity in methamphetamine dependence: a pilot study. Brain Behav. 2014;4:867-76. 
6. Boecker R, Holz N, Buchmann A, Blomeyer D, Plichta M, Wolf I, Baumeister S, Meyer-Lindenberg A, Banaschewski T, Brandeis D, Laucht M. Impact of early life adversity on reward processing in young adults: EEG-fMRI results from a prospective study over 25 years. PLOS ONE. 2014;9:e104185.

7. Kosten T, Miserendino M, Kehoe P. Enhanced acquisition of cocaine self-administration in adult rats with neonatal isolation stress experience. Brain Res. 2000:875:44-50.

8. Der-Avakian A, Markou A. Neonatal maternal separation exacerbates the reward-enhancing effect of acute amphetamine administration and the anhedonic effect of repeated social defeat in adult rats. Neuroscience. 2010:170:1189-98.

9. Li M, Xue X, Shao S, Shao F, Wang W. Cognitive, emotional and neurochemical effects of repeated maternal separation in adolescent rats. Brain Res. 2013;1518:82-90.

10. Volkow ND, Koob G, Baler R. Biomarkers in substance use disorders. ACS Chem Neurosci. 2015;6:522-5.

11. Dalley JW, Fryer TD, Brichard L, Robinson ES, Theobald DE, Lääne K, Peña Y, Murphy ER, Shah Y, Probst K, et al. Nucleus accumbens D2/3 receptors predict trait impulsivity and cocaine reinforcement. Science. 2007:315:1267-70.

12. Cook EH, Stein MA, Krasowski MD, Cox NJ, Olkon DM, Kieffer JE, Leventhal BL. Association of attention-deficit disorder and the dopamine transporter gene. Am J Hum Genet. 1995;56:993-8.

13. Barr CL, Xu C, Kroft J, Feng Y, Wigg K, Zai G, Tannock R, Schachar R, Malone M, Roberts W, et al. Haplotype study of three polymorphisms at the dopamine transporter locus confirm linkage to attention-deficit/hyperactivity disorder. Biol Psychiatry. 2001;49:333-9.

14. Pasini A, Sinibaldi L, Paloscia C, Douzgou S, Pitzianti M, Romeo E, Curatolo P. Pizzuti A. Neurocognitive effects of methylphenidate on ADHD children with different DAT genotypes: a longitudinal open label trial. Eur J Paediatr Neurol. 2013;17:407-14.

15. Riddle E, Fleckenstein A, Hanson G. Mechanisms of methamphetamineinduced dopaminergic neurotoxicity. AAPS J. 2006:8:E413-8.

16. Tobler PN. Behavioral Functions of Dopamine Neurons. In: Iversen L, Iversen S, Dunnett S, Bjorklund A, editors. Dopamine Handbook. 1st ed. New York: Oxford University Press; 2010. p. 316-30.

17. Sagvolden T. Behavioral validation of the spontaneously hypertensive rat (SHR) as an animal model of attention-deficit/hyperactivity disorder (AD/ HD). Neurosci Biobehav Rev. 2000;24:31-9.

18. Sagvolden T, Russell V, Aase H, Johansen E, Farshbaf M. Rodent models of attention-deficit/hyperactivity disorder. Biol Psychiatry. 2005:57:1239-47.

19. Russell V. Neurobiology of animal models of attention-deficit hyperactivity disorder. J Neurosci Methods. 2007:161:185-98.

20. Womersley JS, Hsieh JH, Kellaway LA, Gerhardt GA, Russell VA. Maternal separation affects dopamine transporter function in the spontaneously hypertensive rat: an in vivo electrochemical study. Behav Brain Funct. 2011;7:49.

21. Womersley JS, Kellaway LA, Stein DJ, Gerhardt GA, Russell VA. Effect of cocaine on striatal dopamine clearance in a rat model of developmental stress and attention-deficit/hyperactivity disorder. Stress. 2016;19:78-82.

22. Barr AM, Panenka WJ, MacEwan GW, Thornton AE, Lang DJ, Honer WG, Lecomte T. The need for speed: an update on methamphetamine addiction. J Psychiatry Neurosci. 2006;31:301-13.

23. Garza RDL, Mahoney J. A distinct neurochemical profile in WKY rats at baseline and in response to acute stress: implications for animal models of anxiety and depression. Brain Res. 2004:1021:209-18.

24. Sagvolden T, Johansen EB, Wøien G, Walaas SI, Storm-Mathisen J, Bergersen $\mathrm{LH}$, Hvalby $\mathrm{O}$, Jensen V, Aase H, Russell VA, et al. The spontaneously hypertensive rat model of ADHD-the importance of selecting the appropriate reference strain. Neuropharmacology. 2009;57:619-26.

25. Kandel D, Logan J. Patterns of drug use from adolescence to young adulthood: I. Periods of risk for initiation, continued use, and discontinuation. Am J Public Health. 1984;74:660-6.

26. Okamoto K, Aoki K. Development of a strain of spontaneously hypertensive rats. Jpn Circ J. 1963;27:282-93.

27. Carlezon WA. Place conditioning to study drug reward and aversion. Methods Mol Med. 2003:84:243-9.

28. SABS: South African National Standard. The Care and Use of Animals for Scientific Purposes (SANS 10386:2008). 1st edn. Pretoria: South African Bureau of Standards, Standards Division; 2008.
29. Mohr B. The current status of laboratory animal ethics in South Africa. ATLA. 2013;41:48-51.

30. Daniels WM, Pietersen CY, Carstens ME, Stein DJ. Maternal separation in rats leads to anxiety-like behavior and a blunted ACTH response and altered neurotransmitter levels in response to a subsequent stressor. Metab Brain Dis. 2004;19:3-14

31. Kosten TA, Huang W, Nielsen DA. Sex and litter effects on anxiety and DNA methylation levels of stress and neurotrophin genes in adolescent rats. Dev Psychobiol. 2014:56:392-406.

32. Kosten TA, Nielsen DA. Litter and sex effects on maternal behavior and DNA methylation of the $\mathrm{Nr} 3 \mathrm{C} 1$ exon 17 promoter gene in hippocampus and cerebellum. Int J Dev Neurosci. 2014;36:5-12.

33. Volkow ND. What do we know about drug addiction? Am J Psychiatry. 2005;162:1401-2.

34. Wultz B, Sagvolden T, Moser E, Moser M. The spontaneously hypertensive rat as an animal model of attention-deficit hyperactivity disorder: effects of methylphenidate on exploratory behavior. Behav Neural Biol. 1990:53:88-102.

35. Faure J, Stein D, Daniels W. Maternal separation fails to render animals more susceptible to methamphetamine-induced conditioned place preference. Metab Brain Dis. 2009;24:541-59.

36. Silva CD, Neves AF, Dias Al, Freitas HJ, Mendes SM, Pita I, Viana SD, Oliveira PAD, Cunha RA, Ribeiro CAF. A single neurotoxic dose of methamphetamine induces a long-lasting depressive-like behaviour in mice. Neurotox Res. 2014;25:295-304

37. dela Peña I, Ahn H, Choi J, Shin C, Ryu J, Cheong J. Reinforcing effects of methamphetamine in an animal model of attention-deficit/hyperactivity disorder- the spontaneously hypertensive rat. Behav Brain Funct. 2010;6:72.

38. dela Peña I, Lee JC, Lee HL, Woo TS, Lee HC, Sohn AR, Cheong JH. Differential behavioral responses of the spontaneously hypertensive rat to methylphenidate and methamphetamine: lack of a rewarding effect of repeated methylphenidate treatment. Neurosci Lett. 2012:514:189-93.

39. Zhang Y, Loonam T, Noailles P, Angulo J. Comparison of cocaine- and methamphetamine-evoked dopamine and glutamate overflow in somatodendritic and terminal field regions of the rat brain during acute, chronic, and early withdrawal conditions. Ann NY Acad Sci. 2001:937:93-120

40. Wobbrock J, Findlater L, Gergle D, Higgins J. The aligned rank transform for nonparametric factorial analyses using only ANOVA procedures In Proceedings of the ACM Conference on Human Factors in Computing Systems (CHI'11). New York: ACM Press; 2011. p. 143-6.

41. Lehner MH, Taracha E, Kaniuga E, Wisłowska-Stanek A, Wróbel J, Sobolewska A, Turzyńska D, Skórzewska A, Płaźnik A. High-anxiety rats are less sensitive to the rewarding affects of amphetamine on $50 \mathrm{kHz}$ USV. Behav Brain Res. 2014:275:234-42.

42. Roberts W, Peters J, Adams Z, Lynam D, Milich R. Identifying the facets of impulsivity that explain the relation between ADHD symptoms and substance use in a nonclinical sample. Addict Behav. 2014;39:1272-7.

43. dela Peña I, Ahn H, Choi J, Shin C, Ryu J, Cheong J. Methylphenidate selfadministration and conditioned place preference in an animal model of attention-deficit hyperactivity disorder: the spontaneously hypertensive rat. Behav Pharmacol. 2011:22:31-9.

44. dela Peña I, de la Peña J, Kim B, Han D, Noh M, Cheong J. Gene expression profiling in the striatum of amphetamine-treated spontaneously hypertensive rats which showed amphetamine conditioned place preference and self-administration. Arch Pharm Res. 2015:38:865-75.

45. Yang P, Cuellar D III, Swann A, Dafny N. Age and genetic strain differences in response to chronic methylphenidate administration. Behav Brain Res. 2011:218:206-17.

46. Yang P, Swann A, Dafny N. Acute and chronic methylphenidate doseresponse assessment on three adolescent male rat strains. Brain Res Bull. 2006;71:301-10.

47. Langen B, Dost R. Comparison of SHR, WKY and Wistar rats in different behavioural animal models: effect of dopamine D1 and alpha2 agonists. Atten Defic Hyperact Disord. 2011;3:1-12.

48. Everitt BJ, Robbins TW. From the ventral to the dorsal striatum: devolving views of their roles in drug addiction. Neurosci Biobehav Rev. 2013:37:1946-54

49. Kelley A. Measurement of rodent stereotyped behavior. Curr Protoc Neurosci. 2001:4:8.8.1-8.13. 
50. Camp D, Browman K, Robinson T. The effects of methamphetamine and cocaine on motor behavior and extracellular dopamine in the ventral striatum of Lewis versus Fischer 344 rats. Brain Res. 1994;668:180-93.

51. McCarty R, Chiueh C, Kopin I. Differential behavioral responses of spontaneously hypertensive (SHR) and normotensive (WKY) rats to d-amphetamine. Pharmacol Biochem Behav. 1980;12:53-9.

52. Knackstedt $L$, Kalivas P. Extended access to cocaine self-administration enhances drug-primed reinstatement but not behavioral sensitization. J Pharmacol Exp Ther. 2007;322:1103-9.

53. Eisener-Dorman AF, Grabowski-Boase L, Tarantino LM. Cocaine locomotor activation, sensitization and place preference in six inbred strains of mice Behav Brain Funct. 2011;7:29.

54. Watanabe Y, Fujita M, Ito Y, Okada T, Kusuoka H, Nishimura T. Brain dopamine transporter in spontaneously hypertensive rats. J Nucl Med. 1997;38:470-4.

55. Myers M, Whittemore S, Hendley E. Changes in catecholamine neuronal uptake and receptor binding in the brains of spontaneously hypertensive rats (SHR). Brain Res. 1981;220:325-38.

56. Provençal N, Binder E. The effects of early life stress on the epigenome: from the womb to adulthood and even before. Exp Neurol. 2015;268:10-20

57. Antonopoulos J, Dori I, Dinopoulos A, Chiotelli M, Parnavelas J. Postnatal development of the dopaminergic system of the striatum in the rat. Neuroscience. 2002;110:245-56.
58. Marco EM, Macrì S, Laviola G. Critical age windows for neurodevelopmental psychiatric disorders: evidence from animal models. Neurotox Res. 2011;19:286-307.

59. Money K, Stanwood G. Developmental origins of brain disorders: roles for dopamine. Front Cell Neurosci. 2013;7:260.

60. Martin LJ, Spicer DM, Lewis MH, Gluck JP, Cork LC. Social deprivation of infant rhesus monkeys alters the chemoarchitecture of the brain: I, subcortical regions. J Neurosci. 1991;11:3344-58.

61. Cagniard B, Sotnikova T, Gainetdinov R, Zhuang X. The dopamine transporter expression level differentially affects responses to cocaine and amphetamine. J Neurogenet. 2014;28:112-21.

62. Stein MA, Waldman I, Newcorn J, Bishop J, Kittles R, Cook EH. Dopamine transporter genotype and stimulant dose-response in youth with attention-deficit/hyperactivity disorder. J Child Adolesc Psychopharmacol. 2014;24:238-44.

63. Womersley JS, Mpeta B, Dimatelis JJ, Kellaway LA, Stein DJ, Russell VA. Developmental stress elicits preference for methamphetamine in the spontaneously hypertensive rat model of attention-deficit/hyperactivity disorder. Zenodo. 2016. doi:10.5281/zenodo.52569.

\section{Submit your next manuscript to BioMed Central and we will help you at every step:}

- We accept pre-submission inquiries

- Our selector tool helps you to find the most relevant journal

- We provide round the clock customer support

- Convenient online submission

- Thorough peer review

- Inclusion in PubMed and all major indexing services

- Maximum visibility for your research

Submit your manuscript at www.biomedcentral.com/submit 